Ciudad, mujer y conflicto: el comercio ambulante en el D.F. José Luis Lezama*

El propósito de este trabajo es analizar las características socioeconómicas generales de un grupo de vendedoras ambulantes del Centro Histórico de la Ciudad de México, contextualizándolo en el marco sociopolítico del comercio ambulante de la Ciudad de México.

Una primera parte la constituye una presentación del tema mujer y trabajo; a continuación se realiza una problematización de los actores más directamente involucrados en el comercio ambulante en el Distrito Federal. Finalmente se hace una descripción y recapitulación de las características generales de las mujeres ocupadas en esta actividad.

\title{
Antecedentes históricos
}

Los años cuarenta son considerados por diversos autores como fundamentales para la evolución posterior del país, porque en ellos empiezan a consolidarse algunas de las tendencias más claras de un modelo de desarrollo que, ya desde loš años treinta, se venía configurando; éste se basó en una industrialización que, al menos en su primera etapa, pareció representar una alternativa de desarrollo autónomo y autosostenido para México.

No obstante, a pesar de sus logros iniciales, el proceso económico no devino en un desarrollo integral, reduciéndose en sus aspectos más esenciales a un intenso incremento de los indicadores económicos, pero en el contexto de grandes desigualdades y de un progresivo deterioro de las condiciones de vida de grandes sectores de la población. Entre 1940 y 1970 la economía mexicana se desarrolló de manera insólita, llegando incluso a hablarse de un "milagro económico mexicano". En este periodo el país creció a una tasa anual superior a $6 \%$ (más de $3 \%$ per cápita). La producción manufacturera se elevó en más de $8 \%$. En 1960, por ejemplo, tan sólo el sector agrícola empleaba a más de $65 \%$ de la fuerza de trabajo, aportando poco más de $23 \%$ del producto interno bruto; no obstante, para 1970 la relación había cambiado rotundamente, pues dicho sector sólo absorbía la mitad de la fuerza de trabajo señalada y contribuía únicamente con $16 \%$ del producto interno

* Profesor-investigador del Centro de Estudios Demográficos y de Desarrollo Urbano de El Colegio de México. 
bruto. Las actividades manufactureras pasaron de representar $17.8 \%$ del PIB a $26 \%$ y a absorber $16 \%$ de la fuerza de trabajo. Este proceso de industrialización en México logró que, para 1970, el país fuera autosuficiente en la producción de alimentos, petróleo, acero y otros bienes de consumo (Hansen, 1983: 57). Entre 1940 y 1970 el modelo de desarrollo mexicano había logrado sus objetivos económicos más importantes; no obstante, las metas del desarrollo social no corrieron la misma suerte, lo cual se hizo evidente en los problemas de distribución de la riqueza que pronto denotaron la presencia de grandes contrastes entre pequeños grupos enriquecidos y una gran proporción de la población que empezó a mostrar claros síntomas de empobrecimiento (Hewitt, 1977).

Para 1970 el país contaba con $44.7 \%$ de su población asentada en ciudades y las tendencias demográficas a la concentración se combinaban con la de las actividades económicas. Estos años, aún con los ingresos petroleros, son años de crisis. En 1970 el desempleo afecta a $35 \%$ de la PEA en el D.F. y para fines de la década se estiman cifras de subempleo cercanas a 50\% (Schteingart y Perló, 1984: 112).

La fuerte industrialización no sólo dio lugar a nuevas actividades en el campo de la producción, la comercialización y el consumo, sino que también generó nuevos grupos sociales y el fortalecimiento de algunos de los existentes. Además de surgir y ampliarse segmentos completos de la clase media, se multiplicaron también los grupos populares, desempleados y subempleados que ya no tenían cabida en la estructura económica y que poco a poco fueron conformando los distintos sectores de la informalidad.

El Estado, impulsor principal del desarrol]o, se enfrentó además ante el problema de satisfacer el conjunto de demandas urbanas de estos grupos sociales que el proceso de urbanización había generado. Los medios de consumo colectivo se constituyeron en uno de los rubros del gasto social más significativo, precisamente por la magnitud de la población de ciudades como la de México, y comenzaron a replantearse también como elemento de negociación y fuente de conflicto entre distintos agentes sociales. La población que se había concentrado en las ciudades debido a la migración. en parte respondía a las necesidades básicas del desarrollo industrial. Por ello, pareció adaptarse de manera adecuada a las necesidades de la industria y servicios que demandaban mano de obra abundante y barata. La ciudad se convirtió, por lo tanto, en un apoyo fundamental para el proceso de industrialización, puesto que puso al alcance del capital una fuerza de trabajo que, por su bajo costo de reproducción, amplió los márgenes de ganancia de las distintas empresas capitalistas allí instaladas. Por ello, puede 
decirse que la escasa inversión en medios de consumo colectivo para los grupos populares y los bajos salarios facilitaron una fuerte y rápida acumulación de capital.

Desde principios de los años setenta, y como un resultado de la crisis del modelo de desarrollo mexicano, las reivindicaciones urbanas se convierten en objetivo de lucha popular, pues la pobreza y el desempleo parecían extenderse a diversos sectores de la población; pero la conflictividad del espacio urbano se agranda por la multiplicación de las demandas y de los grupos sociales que las sustentan. Así, por ejemplo, a los contingentes populares se suman las clases medias y altas, añadiendo a la serie de demandas básicas de los pobres, aquellas que tienen que ver con la seguridad pública, la calidad de los servicios, las demandas de áreas verdes y la defensa de] medio ambiente.

En los primeros tiempos de la urbanización, el Estado pudo manejar las situaciones potencialmente conflictivas y contrarrestar a las organizaciones urbanas que surgían. Parte de el]o se explica por la capacidad del modelo económico para ofrecer paliativos a importantes grupos sociales; el resultado fue un cierto grado de movilidad y el cumplimiento de algunas expectativas. Cuando esto no fue suficiente, los métodos fueron la concesión, la coptación y la represión; entre otros recursos el Estado se valió de la estructura partidista para atraer a una parte significativa de los nuevos sujetos urbanos que pudieran representar una oposición a las políticas del Estado. Para esto creó, dentro de la estructura corporativa del PRI, a la CNOP. No obstante, después de los setenta, estas medidas ya no fueron capaces de contener la explosión de distintas organizaciones que, precisamente, se multiplicaban por el deterioro de las condiciones de vida en general.

En este contexto de fines de los setenta y principios de los ochenta, conforme se acentúa la crisis económica y la ciudadanía se concientiza en distintos ámbitos de lo político, se va gestando, paso a paso, una conciencia de los problemas urbanos que pronto se convertirán en objeto de reivindicación.

\section{Mujer, familia y trabajo}

Si bien el proceso de descomposición del modelo de desarrollo mexicano es paulatino, a partir de los años setenta se hace más evidente. Algunos de sus signos son la caída de las tasas de crecimiento económico, e] aumento de] desempleo, modificaciones en él perfil migratorio y, como veremos, cambios en la relación entre familia y empleo. 
Distintos estudios, tanto de México como de otros paises de América Latina señalan el surgimiento y generalización de importantes sectores de la sociedad que no logran ser incorporados al trabajo productivo desde los inicios mismos de la industrialización, allá por los años treinta y cuarenta. Esto que aparecía como una tendencia inherente al desarrollo del capitalismo en la región, muestra a partir de los setenta una acentuación significativa por la profundización de la crisis y, en el caso de México, obliga a importantes núcleos de población a modificar sustancialmente sus formas de reproducción social. Así de una inserción laboral asumida como fenómeno individual, se pasa a una entendida como respuesta colectiva, como grupo social. Es en esta perspectiva que los estudiosos del tema detectan el papel decisivo que empieza a tener la familia como unidad y mediación, a través de la cual el individuo asume los distintos ámbitos de su reproducción social. El trabajo es así emprendido como una actividad que involucra al grupo y por ello la familia despliega estrategias de reproducción mediante las cuales pretende, conciente o inconcientemente, optimizar la utilización de sus recursos humanos para el aprovisionamiento de sus medios de subsistencia.

Los estudios recientes sobre la mujer tanto desde el terreno laboral, como desde el de las relaciones de poder y el que atañe a la vida cotidiana, han demostrado que la participación de la mujer en las actividades económicas no se produce en un ámbito de armonía y concordia sino que más bien está penetrada por el conflicto y la discordia. Éstos derivan de la naturaleza de las relaciones de poder que subyace en las interacciones entre los miembros de la familia y, particularmente, de la relación hombre-mujer, relación de opresión que no es eliminada por la participación femenina en la actividad económica, о рог la mayor capacidad para aportar recursos a la familia que en muchas ocasiones demuestran las mujeres.

La hipótesis general que rige este trabajo sostiene que en el conflicto por la apropiación del espacio público, encabezado por distintos grupos de vendedores ambulantes, se combinan tanto las características socioeconómicas y de género de los actores involucrados, el tipo de composición social (grupos marginados) como la importancia que asume este sector de la población para la sustentación y legitimación de los proyectos y perspectivas electorales de diversos partidos políticos, particularmente el PRI.

Desde el punto de vista conceptual, partimos de la perspectiva de aquellos enfoques analíticos que relacionan la familia y el trabajo femenino con las estrategias de vida instrumentadas por las familias en épocas de crisis y en determinados contextos socioes- 
paciales. En lo referente al conflicto, nos ubicamos en aquella perspectiva analítica según la cual, las fuentes del cambio y del conflicto social deben ser buscadas en todos los ámbitos de la vida social, en la medida en que todos ellos son susceptibles de plantear conflictos por la apropiación de la "historicidad" (Touraine, 1987) o por reapropiarse o transformar los significados urbanos (Castells, 1985).

El trabajo femenino que nos interesa problematizar es el no asalariado, puesto que las vendedoras ambulantes que son nuestro objeto de estudio poseen esta característica general. Este tipo de trabajo puede ser estudiado desde dos recortes teóricos. El primero es aquel que tiene que ver con la discusión sobre el carácter de las relaciones económicas que no están regidas por el salario en el contexto de relaciones capitalistas de producción dominantes; es decir, el estatuto del trabajo no asalariado y las relaciones de éste con el resto de la sociedad. Un segundo recorte se refiere al análisis de las formas de reproducción de las familias no asalariadas, así como a los mecanismos de que se valen para ello. Esto quiere decir: las formas específicas en que las familias conciben la sociedad de la que forman parte desde la perspectiva de su reproducción socio-económica. Como no todos los no asalariados son pobres ni viven, por tanto, en condiciones de precariedad, es necesario aclarar que, dentro de las actividades ambulantes desempeñadas por las mujeres objeto de nuestro estudio, consideraremos a aquellos grupos de no asalariados calíficados como pobres o marginados.

La primera perspectiva o recorte tiene que ver con la forma bajo la cual se insertan los llamados grupos marginados o informales en la economía mayor que los envuelve.

Sobre este punto se han elaborado diversas conjeturas; algunas de ellas, por ejemplo, ven a las economías de subsistencia como generadoras de mano de obra permanente para las economías capitalistas. Estas economías de subsistencia mantienen una relación funcional de producción y reproducción de la fuerza de trabajo de acuerdo con las necesidades de la sociedad capitalista tanto en épocas de auge como en periodos de crisis (Meillasoux, 1983). El comercio ambulante y en este caso el practicado por la mujer, puede ser visto como uno de los aspectos de esta reproducción de la fuerza de trabajo bajo el régimen de una economía capitalista, a la cual se vincularía por aquello que Benholdt-Thomsen (1982) llama el sector de producción de subsistencias, en el cual también se incluiría el trabajo doméstico realizado por la mujer en el ámbito familiar. La sobrevivencia misma de la sociedad capitalista dependería incluso de la persistencia dentro o fuera de sus 
límites territoriales de una economía doméstica encargada total o parcialmente de la producción y reproducción de la fuerza de trabajo (Meillasoux, 1983). La permanencia de las economías domésticas ha sido pensada por diversos autores de la realidad latinoamericana como favorable, en algunos casos, a la acumulación de capital y, en otros, como abiertos obstáculos a la modernización capitalista. La teoría de la marginalidad, por ejemplo, estableció como uno de los rasgos de las economías capitalistas dependientes no la presencia de los marginados y de las economías de subsistencia, sino la gran magnitud que ambos elementos poseían en América Latina.

De alguna manera, los teóricos del sector informal, dentro del cual se incluiría también al comercio ambulante, sostienen que la informalidad resulta del gran crecimiento natural y social de la población que no es absorbida por los sectores modernos (García, 1989).

El desarrollo actual de la polémica sobre las economías de subsistencia y la marginalidad ha desembocado en la discusión sobre aquello que es considerado por algunos como la economía subterránea, planteándose incluso la existencia de un sistema económico paralelo al formal, que lo alimenta y sustenta en los actuales momentos de crisis y de replanteamiento en las estrategias productivas a nivel internacional. Este sistema conformado por la informalidad vendria a constituir una alternativa para la acumulación capitalista que permitiría, no sólo abaratar el costo de la fuerza de trabajo, sino de procesos productivos completos.

En relación con el objeto de nuestra investigación que son las vendedoras ambulantes, nos interesa esta discusión en torno a la participación no asalariada de la mujer en la economía, puesio que el trabajo en el comercio ambulante no se da bajo la forma de una relación laboral, sino con la intermediación de diversas relaciones de carácter informal.

Nuestra posición respecto a esta polémica es que la presencia de sectores no capitalistas en la sociedad mexicana no obedece a un desajuste circunstancial, superable con la llegada de un capitalismo más desarrollado, sino que, por el contrario, constituye la forma natural de ser de las sociedades capitalistas periféricas, estableciéndose entre estos sectores y los propiamente capitalistas, relaciones de adecuación que hacen posible, de manera asimétrica, Ja reproducción social.

Desde la perspectiva del segundo recorte en el que ubicamos nuestro trabajo, es decir, el del nivel familiar, partimos de una definición de familia entendida como unidad doméstica. es decir. aquellos grupos -en la mayor parte de los casos- que comparten 
una vivienda y que llevan a cabo una economía en común (Margulis, s/f). Éstas poseen las más de las veces un núcleo central, aunque pueden contar con más de uno, dependiendo del tipo y extensión de la familia de que se trate. La forma de reproducción de las unidades domésticas se da por medio de la participación de todos sus miembros y en ocasiones los miembros de otras unidades. Esta definición es algo similar a la utilizada por algunos autores [García, de Oliveira y Muñoz, 1983) cuando se refieren a los hogares como aquel ámbito social en el cual las personas efectúan en común las actividades requeridas para su reproducción. Así se sostiene que en el interior de las familias se efectúa una división funcional y estratégica de actividades, que permite a algunos miembros ya sea trabajar fuera o dentro de la casa, estudiar, cuidar a los niños, etcétera.

Nos interesa en esta parte enfatizar no el lado activo del capital, sino el de las familias. Esto quiere decir que, bajo el recorte de la unidad doméstica, resaltamos el aspecto de las estrategias de reproducción no capitalistas, como búsqueda de opciones laborales, cuando el capital se muestra incapaz o no interesado en su reproducción. Hablamos pues de relaciones no capitalistas que surgen o se sostienen como mecanismos de reproducción implantados por las unidades domésticas de la economía urbana, ante la incapacidad del capital de absorber, bajo los mecanismos formales, toda la fuerza de trabajo que existe en una formación social determinada, ya sea por las continuas crisis a las que se enfrenta la economía capitalista o por el desplazamiento de población generado por la alta tecnificación de los procesos productivos. Pero sin dejar de lado que, por otra parte, desde el punto de vista activo del capital, las formas no asalariadas y los procesos productivos considerados informales en general, constituyen también estrategias y alternativas de reproducción creadas por el capital en su búsqueda por disminuir los costos de producción.

Las respuestas de las unidades domésticas pueden ser, como ha sido planteado por algunos investigadores (Margulis, s/f) como una reproducción que se sustenta en torno a la disponibilidad y asignación de fuerza de trabajo, ya sea en relaciones de tipo capitalista o no, o en combinaciones de ambas. La lógica de estas unidades sería la maximización del uso de la fuerza de trabajo con el objetivo de obtener ingresos monetarios. Como ya se ha mencionado (Margulis, s/f), el bienestar de las unidades domésticas estaría vinculado a la relación interna entre productores y consumidores de ingresos, dependiendo esto del momento del ciclo biológico familiar. En este sentido, entre más productores de ingresos existan, mayores posibilidades tendría la unidad doméstica 
de sobrevivir, pero también de establecer proyectos a futuro que incluya el bienestar de los hijos a mediano y largo plazos.

Estas definiciones de la unidad doméstica o del hogar como ámbito común de reproducción para grupos unidos, no necesariamente por lazos de parentesco, supone también la presencia de una cierta ideología muy consolidada que enaltece y destaca los principios de solidaridad y que antepone el interés del grupo al individual en la búsqueda de los objetivos comunes.

No obstante, como ya se ha mencionado, al margen de esta ideología, en los hechos los miembros de las familias, y particularmente la mujer, asumen, en muchas ocasiones, estas estrategias de vida bajo diversas formas de conflicto, lo que resulta de su inserción en relaciones de poder que la sitúan en condiciones domésticas de desigualdad.

A pesar de lo anterior, la unidad doméstica es entendida como un conjunto de estrategias armónicas o conflictivas comunes instauradas para asegurar su reproducción. En un conocido estudio sobre ciudades de México y Brasil [García, de Oliveira y Muñoz] se sostiene que las familias asumen su reproducción de manera conjunta estableciendo estrategias que incluyen tanto el trabajo intra como el extradoméstico, es decir, tanto la generación de valores de uso como de valores de cambio. Siempre que hay condiciones para hacerlo los miembros de las familias incrementan su. participación económica; pero cuando no existen oportunidades en el sector de producción de mercancías, se insertan en cualquier actividad que les posibilite un ingreso. En periodos de crisis, o en los casos señalados de readecuaciones en las estrategias productivas del capital, las familias que no encuentran alternativas en la economía formal, se distribuyen en mayor medida en actividades no directamente capitalistas, en aquellas del llamado sector informal.

Otra de las hipótesis que establecimos sostiene que las caracteristicas generales de las mujeres que trabajan en el comercio ambulante son, en alguna medida, similares a las de aquellas que lo hacen en la economía formal. Por ejemplo, la mayor participación de las del grupo de edad de 20 a 24 años, de las solteras, separadas o viudas en relación con las casadas, de las que tienen un menor número de hijos pequeños, así como de las que cuentan con la presencia de otra mujer en el hogar, tal como lo señalan los hallazgos de Orlandina de Oliveira (1989).

Según los trabajos recientes de Brígida García y Orlandina de Oliveira, se ha observado un significativo incremento del trabajo femenino en los últimos años, destacando, en esta mayor participación económica de la mujer, el hecho de que además de las jóve- 
nes, sin hijos y con mayor escolaridad, en el periodo 1976-1987, se ha notado una presencia muy importante de mujeres de mayor edad, con hijos y con baja o nula escolaridad. Estas autoras relacionan tal fenómeno con la crisis económica mexicana de los años ochenta, la cual empujó hacia el mercado de trabajo a un mayor número de mujeres, con el propósito de contribuir al gasto familiar o para mantener los niveles de vida cuando éstos se vieron amenazados por la disminución del poder adquisitivo.

Considero que este proceso ligado a la crisis de los ochenta explica en mayor medida, tanto la proliferación del comercio ambulante, como el incremento del trabajo femenino en este sector; incluso este último puede ser un síntoma de la profundización de la crisis, si partimos del supuesto de que la mujer se incorpora a la actividad económica muchas veces después de que el ingreso generado por el hombre resulta insuficiente para cubrir las necesidảdes de la familia. Esto lo considero así porque las actividades informales se convierten en una de las pocas alternativas de reproducción para muchas familias cuando la crisis contrae el empleo en general y porque además el sector informal, aun cuando constituye una forma de extorsión económica y una alternativa para la acumulación, también es funcional para un tipo específico de oferta de fuerza de trabajo como es el caso de la femenina, la cual no siempre reúne los requisitos de la economía formal.

En lo que se refiere al comercio ambulante, se encuentran algunas características particulares vinculadas al género, o al menos que reflejan la precariedad de la inserción del trabajo femenino en la estructura económica. En este sector es frecuente encontrar a la mujer como sostén principal del hogar y a pesar de la ayuda familiar para la realización de las tareas domésticas, quizás sea mayor la proporción de mujeres que se encargan de todo o la mayor parte de las labores del hogar, incluido el cuidado de los niños. Esta hipótesis descansa en el hecho de que dado el carácter informal de la actividad que desempeña, el comercio ambulante se adapta más a las características de la mujer en su condjción de madre y jefa del hogar. Al ubicarse en estas actividades, en algunas ocasiones cuenta con la ventaja de no tener que cumplir horarios fijos, de ajustar la jornada de trabajo según sus necesidades e íncluso cargar con los hijos cuando no existe quien se ocupe de ellos.

El trabajo de la mujer en actividades como el comercio ambulante opera una doble función reproductiva. Por una parte, constituye una alternativa de empleo para sujetos que no encuentran otras opciones de trabajo; por lo tanto, o bien contribuyen al gasto familiar o, en el caso de las que son jefas, sostienen completamen- 
te a sus familias. Por otra parte, participan en la reproducción de la fuerza de trabajo de distintos grupos sociales pobres por los menores costos de los productos que exponen. A diferencia del trabajo doméstico, éste no se realiza o no se incorpora a la producción capitalista con la intermediación directa del marido cuya fuerza de trabajo reproduce la trabajadora doméstica, sino con la intermediación del mercado, aun cuando sea informal, donde colocan sus productos. Por supuesto, esto no evita la sumisión al esposo y la reproducción de la fuerza de trabajo de éste en el ámbito del hogar, más bien permitiría hablar de una triple reproducción efectuada por este sector de la población femenina: la reproducción biológica, la de la fuerza de trabajo dentro de la familia y la de la fuerza de trabajo fuera de la familia por la vía de los productos que vende en el mercado.

\section{Comercio ambulante, ciudad y conflicto social}

La disputa actual entre comercio ambulante y comercio establecido se ubica en distintos niveles de la problemática de la ciudad. Lo consideramos como parte de los problemas urbanos porque, por un lado, la disputa por el espacio público de la ciudad y su posibilidad de ser o no apropiado por la vía privada constituye una auténtica reivindicación urbana, y en segundo lugar, porque en torno a la problemática se conforman o redefinen grupos sociales que, en función de sus luchas y confrontaciones, pretenden modificar o redefinir los usos posibles del espacio de la ciudad de México. Pero esto que se expresa como una lucha por el espacio, sintetiza el enfrentamiento de importantes fuerzas económicas y da cuenta de la potencialidad política de un problema, supuestamente secundario, dentro de los de mayor magnitud que enfrenta la ciudad de México (contaminación, seguridad, transporte, etcétera).

El tema de los ambulantes hace recordar el concepto de "población marginal", que fue muy recurrido por la sociología latinoamericana. Algunos sociólogos hablan, refiriéndose a los marginados, de conductas desarticuladas, de un estilo de vida y una cultura (la cultura de la pobreza), así como una forma particular de asumir la política caracterizada, ante todo, por la indiferencia, e] rechazo a toda forma partidista y la incapacidad para lograr una verdadera autorrepresentación política. Ésta la ceden a una fuerza exterior que los protege o, en su caso, los castiga. Constituyen un sector cuyo rasgo más evidente es la apatía; sólo el hambre y la sobrevivencia los animan a la movilización, y sólo cuando el hambre y el conflicto político confluyen y se confunden en una 
coyuntura especifica, devienen en agentes del cambio. No obstante, nosotros sostenemos que independientemente de la presencia de algunas de la características descritas, esta población marginada o pobre, cuando se enfrenta a situaciones extremas de pobreza y carencias, radicaliza sus posiciones convirtiéndose, junto con otros actores, en agentes significativos del cambio social.

La categoría "vendedor ambulante" encierra una gran complejidad y es ésta la que explica las dificultades para su tratamiento analítico y para la solución del conflicto que se plantea en el plano de lo político.

Para empezar, esta definición encubre una gran heterogeneidad social. Bajo ella se confunden actividades y protagonistas disímbolos y, en alguna medida, reproduce la propia complejidad de la ciudad. Para la acepción más usual, un vendedor ambulante estaría representado por un simple ciudadano, regularmente pobre, cuyo único espacio de reproducción económica es la calle. Esta situación económica tomaría cuerpo en la categoría social del "vendedor por cuenta propia", el merolico o el saltimbanqui; todos ellos presentes en el mercado de la ciudad, como vendedores de un producto o prestadores de un servicio.

Obviamente, en el actual conflicto que nos ocupa, ésta no es la única figura social ni es la más importante. Está, además, todo un sector de comerciantes con una amplia y sólida organización, cuya actividad principal es la introducción y distribución ilícita de productos importados. Incluso, en el plano de la conjetura, se menciona no sólo la participación de importantes intereses económicos, sino también la de algunas instancias gubernamentales.

El sector encargado de la distribución de estos productos de origen extranjero, salvo en contadas ocasiones, no reuniría las características básicas del vendedor ambulante a que hemos hecho referencia. Más bien estaría integrado por intermediarios, asalariados o comisionistas de una categoría económica y de una figura social no transparente pero real, con una fuerte influencia en el plano de la negociación política. El vendedor ambulante constituiría su expresión visible, la manifestación de una de las partes que lo integran, pero también el ocultamiento de lo más esencial.

Existe otra figura no menos real, pero también no menos confusa, que es la del "invidente". Ésta funciona, en muchos casos, como el pretexto o la expresión formal de las fuerzas que en verdad actúan en los niveles de mayor grado de eficacia pero, de muchas maneras, el invidente es una fuerza social actuante, que legitima su presencia en el escenario del conflicto por la vía de ese ámbito de lo formal al que le debe su existencia, ámbito creado por decisión misma del gobierno quien es, al final de cuentas, res- 
ponsable de su existencia. El invidente justifica al menos una de las entradas en la escena de lo formal del vendedor ambulante, dándole su estatuto de legalidad. El invidente, sea que directamente ejerza el comercio, o que actúe como intermediario de la actividad ambulante, permite al Estado figurar en su papel de protector de los desvalidos. Mediante este acto el propio Estado le da un carácter social a la concesión por el uso de una fracción del espacio urbano. La figura social del invidente permite, en algunas ocasiones, entrar en la esfera de la legalidad a fuerzas económicas que de otra manera deberían ser consideradas fuera del orden jurídico. Es necesario decir que, por supuesto, dentro de los propios invidentes existen grupos que controlan directamente diversos espacios económicos que los convierten en sujetos con una importante fuerza política.

Pero la verdadera contraparte, la fuerza y grupo de presión real a la que se enfrenta el vendedor ambulante, o lo que él representa, es el comercio organizado. Por ello los comerciantes del centro de la ciudad (que son los directamente afectados por esta actividad) y la propia Canaco, que expresa el interés general del gremio de los comerciantes, aparecen como el verdadero elemento de poder al que deberán enfrentarse las fuerzas económicas y políticas expresadas en el comercio ambulante y el propio Estado, cuando asume su papel de conciliador o cuando se desempeña como uno más de los intereses en conflicto.

El problema es mucho más complejo aún, y lo es por algunas razones, entre las que destacan las siguientes: el comercio organizado legitima su derecho al mercado aludiendo al orden jurídico vigente. Sin embargo, el vendedor ambulante sólo es ilegal bajo la perspectiva de la apropiación (al margen del reglamento de mercados) particular del espacio urbano para efectuar su actividad, y también, por supuesto, por la procedencia ilegal de los productos de algunos de ellos. Pero su actividad es legal y legítimamente válida por los recursos formales de que se vale [y porque es preferible al robo y al ilícito), particularmente bajo la perspectiva de la labor social que desempeña, el desempleo que remedia y el conflicto social que mediatiza. Por ello, a pesar del carácter legal de los intereses que defienden, los comerciantes organizados del centro de la ciudad no pueden legitimar su participación en el conflicto aludiendo a sus simples intereses gremiales, sino que tienen que ampararse bajo el vestuario de una organización, Procéntrico, cuya bandera política es la defensa del Centro Histórico de la Cịudad de México, amenazado supuestamente por la actividad de los ambulantes. Los comerciantes organizados recurren al valor del espacio como símbolo, como patrimonio cultural no de un grupo 
social, sino como territorio de todos, ámbito que permite el reencuentro y la reconciliación genérica de lo mexicano para, bajo esta dimensión de lo sagrado, darle una legitimidad social a sus propios intereses gremiales.

Puede suponerse, con la argumentación del sentido común, cierta relación entre algunos círculos del gobierno y de la iniciativa privada con los distribuidores de los productos de contrabando que inundan el mercado nacional, pero ello nos ubica en el plano de la conjetura y de la especulación. Lo que resulta evidente es la relación casi necesaria entre el Estado y los vendedores ambulantes, bajo la forma que asume el trabajo partidista a estos sectores de la población, es decir, coma clientelismo polftico.

Esto nos permite hablar de otro de los elementos en juego en el conflicto con los ambulantes. Así, creo que algunas de las estrategias políticas de partidos como el PRI (pero no solamente éste) tanto en el pasado como en el momento actual, se han apoyado en una noción de los marginados (entre la que estarfa incluido un sector de los ambulantes) como algo amorfo, homogéneo y fácilmente manipulable.

Visto así, aun de manera superficial, es claro que el problema de los vendedores ambulantes no puede reducisse a una simple confrontación entre comercio informal y comercio organizado, $\mathrm{ni}$ entre autoridades delegacionales y comerciantes. Por lo tanto, comprender el problema y plantear altenativas posibles para su solución, requiere del análisis de todas las fuerzas en conflicto y del peso relativo que cada una de ellas tiene.

En este estudio se abordarán las caracteristicas que asume un pequeño sector de los vendedores ambulantes, haciendo intervenir la variable sexo femenino. Al respecto, proponemos analizar aquí la situación de la mujer que se ocupa del comercio ambulante, destacando un perfil general que incluya características familiares, de trabajo y, en alguna medida, políticas. Más adelante profundizaremos en lo que aquí sólo se esboza bajo su forma general.

\section{Las vendedoras ambulantes del centro histórico de la ciudad de México: características generales}

Uno de los propósitos fundamentales de esta investigación era el de conocer las principales características socioeconómicas de las mujeres ambulantes del Centro Histórico de la Ciudad de México, para de allí derivar algunas interpretaciones sobre las condiciones de vida de la mujer en uno de los ámbitos de la informalidad. De la misma manera, se pretendía obtener información sobre las 
características de orden político, organizativo y de actitudes políticas. Esta última parte fue la menos lograda porque encontramos mucha resistencia ante las preguntas del cuestionario relacionadas con el tema.

Para los propósitos de la investigación se realizó una muestra al azar de 66 mujeres dedicadas al comercio ambulante en el Centro Histórico de la ciudad. Durante el mes de enero de 1991 se entrevistaron mujeres ocupadas en una gran diversidad de actividades, entre las que destacan la venta de aparatos eléctricos, alimentos, juguetes, joyas de fantasía, ropa y zapatos. Los resultados obtenidos de la muestra fueron procesados con el paquete estadístico SAS.

El análisis de los resultados de la muestra lo realizamos de la siguiente manera: primero expusimos las características generales de las 66 mujeres entrevistadas; en segundo lugar, presentamos la descripción de un subgrupo de la muestra integrado por lo que hemos llamado mujer de doble jornada de trabajo. Dicho subgrupo está integrado por 12 mujeres que presentan las siguientes particularidades: 1) trabajan en la vía pública entre 8 y 11 horas; 2) cuidan a los niños y 3) efectúan ellas mismas el trabajo doméstico.

Una primera característica que define al total de las mujeres entrevistadas es que en su mayoría está integrado por jóvenes. De esta manera, de las 66 entrevistadas, $60.61 \%$ caía dentro del rango de 20 a 39 años de edad. No obstante, debe destacarse que se observa una proporción considerable de mujeres de edad avanzada; éstas representaron $13.63 \%$ de la muestra, lo cual es congruente con algunas hipótesis que señalan un significativo incremento en los últimos años tanto del trabajo femenino, como del de los niños y ancianos (García y Oliveira, 1990). Si consideramos el grupo de edad que va de los 40 años en adelante, podemos notar que aquí se concentra $30.3 \%$ de las mujeres estudiadas.

Vendedoras ambulantes por grupos de edad

\begin{tabular}{lr}
\hline Edad & Porcentaje \\
\hline $20-39$ & 60.61 \\
$15-19$ & 9.09 \\
$20-24$ & 15.15 \\
$25-29$ & 15.15 \\
$30-34$ & 10.61 \\
$35-39$ & 19.70 \\
$40-44$ & 12.12 \\
$45-49$ & 4.55 \\
50 y más & 13.63
\end{tabular}

Fuente: encuesta a vendedoras ambulantes del Centro Histórico de la Ciudad de México. 
En relación al estado civil, $62.12 \%$ de las mujeres entrevistadas declararon estar unidas (casadas o en unión libre); $22.73 \%$, solteras; $10.61 \%$, viudas y $4.55 \%$, divorciadas.

Vendedoras ambulantes por estado civil

\begin{tabular}{lc}
\hline Estado civil & Porcentaje \\
\hline Unidas & 62.12 \\
Divorciadas & 4.55 \\
Solteras & 22.73 \\
Viudas & 10.61 \\
\hline
\end{tabular}

Fuente: encuesta a vendedoras ambulantes del Centro Histórico de la Ciudad de México.

Otro dato recabado fue el referente al número de hijos. De la muestra estudiada, $33.33 \%$ tenía hasta dos hijos; $24.24 \%$, de tres a cuatro hijos, y $18.19 \%$, entre cinco y ocho hijos. Por su parte, $24.24 \%$ declaró no tener hijos; estas mujeres fueron básicamente las solteras.

Vendedoras ambulantes por número de hijos

\begin{tabular}{lc}
\hline Número de hijos & Porcentaje \\
\hline $1-2$ & 33.33 \\
$3-4$ & $24.24-57.57$ \\
$5-6$ & 13.64 \\
$7-8$ & 4.55 \\
Ninguno & 24.24 \\
\hline
\end{tabular}

Fuente: encuesta a vendedoras ambulantes del Centro Histórico de la Ciudad de México.

En lo que se refiere a la escolaridad, de las 66 vendedoras ambulantes entrevistadas, $30.31 \%$ estaba en la categoría de primaria incompleta y nula escolaridad; $36.36 \%$ se declaró con primaria completa y $31.82 \%$ tenía secundaria y más. Esto quiere decir que la escolaridad, entre las vendedoras ambulantes, es bastante heterogénea. Existe tanto una alta proporción con niveles ínfimos de escolaridad, como también, en el extremo opuesto, otra con una escolaridad mayor. 
Vendedoras ambulantes por nivel escolar

\begin{tabular}{lc}
\hline Nivel escolar & Porcentaje \\
\hline Sin escolaridad y primaria incompleta & 30.31 \\
Primaria completa & $37.88-68.19$ \\
Secundaria completa & 27.27 \\
Preparatoria o equivalente & 4.55 \\
\hline
\end{tabular}

Fuente: encuesta a vendedoras ambulantes del Centro Histórico de la Ciudad de México.

Acerca de la escolaridad podrían especularse dos hipótesis que permiten explicar esta polarización, por una parte, la encuesta muestra una baja escolaridad y, por otra, da cuenta de una proporción importante de mujeres con secundaria y preparatoria. En primer lugar, la crisis de los setenta y los ochenta parece haber arrojado a las actividades económicas informales a un gran número de personas que, en otras circunstancias (auge económico o de mayor capacidad de absorción de fuerza de trabajo), se pudiera haber colocado en los sectores más dinámicos o en los distintos ámbitos de la economía formal; pero en segundo lugar, en un periodo de crisis económica, el incremento del desempleo no aflora solamente por el contingente de los que antes participaban en la actividad económica como parte de la fuerza de trabajo empleada; esto más bien daría cuenta de la intensidad y generalidad de la crisis. También los grupos de bajos ingresos y aquellos sectores que únicamente de manera esporádica accedían a un empleo, ven a la economía informal como una alternativa de trabajo de mayor estabilidad y permanencia, sobre todo a partir de que la informalidad parece haberse constituido en un elemento estructural de la economía formal, como una estrategia de reproducción ya no sólo de las familias, sino del mismo capital, en la medida en que abarata los costos de producción y de comercialización de los productos. Estaríamos entonces en presencia de un sector informal de la economía que, además de abaratar los costos de reproducción de la fuerza de trabajo por medio de las estrategias familiares de reproducción, abarataría también los costos de producción de las mercancias en la economía capitalista.

Por otro lado, de ser cierto que la migración que llega a la ciudad de México después de los años setenta posee una menor selectividad por ser originaria de regiones rurales cada vez más lejanas, con poca o ninguna experiencia en actividades urbanas, ello explicaría en parte, la baja escolaridad de una significativa proporción de las mujeres entrevistadas, puesto que $62.12 \%$ de ellas no son originarias de la ciudad de México. De esta población 
CIUDAD, MUJER Y CONFLICTO: EL COMERCIO AMBULANTE EN EL D.F. 665

migrante, $50.01 \%$ tiene entre uno y 10 años de haber llegado a la zona metropolitana, es decir, es una migración que arribó en los momentos de crisis.

Vendedoras ambulantes por condición migratoria

\begin{tabular}{lc}
\hline Migrante & Porcentaje \\
\hline Sí & 62.12 \\
No & 37.88
\end{tabular}

Fuente: encuesta a vendedoras ambulantes del Centro Histórico de la Ciudad de Méxjco.

Una característica que destaca es el hecho de que de las 66 vendedoras entrevistadas, en $33.33 \%$ de los casos ellas constituían el único sostén del hogar. No obstante, también es significativo el número de hogares en los cuales el gasto familiar era cubierto por dos personas [37.88\%], independientemente del lugar ocupado en la relación de parentesco.

Vendedoras ambulantes por miembros ocupados

\begin{tabular}{lc}
\hline Miembros & Porcentaje \\
\hline Uno (ella) & 33.33 \\
Dos & $37.88-71.21$ \\
Más de dos & 28.79 \\
\hline
\end{tabular}

Fuente: encuesta a vendedoras ambulantes de] Centro Histórico de la Ciudad de México.

La mayor parte de estas mujeres vivía en familias de tipo nuclear $(74.24 \%$ y el número de sus miembros era en un $63.63 \%$ de una a seis personas. Sin embargo, $30.3 \%$ de estas mujeres viven

Vendedoras ambulantes por tipo de familia

\begin{tabular}{lc}
\hline Tipo de familia & Porcentaje \\
\hline Nuclear & 72.73 \\
Ampliada & 27.27 \\
Miembros & \\
$1-3$ & 24.24 \\
$4-6$ & 39.39 \\
$7-9$ & 21.21 \\
Más de 10 & 15.16 \\
\hline
\end{tabular}

Fuente: encuesta a vendedoras ambulantes del Centro Histórico de la Ciudad de México. 
en familias de entre siete y 12 miembros. Respecto a este último dato, debe decirse también que $42.43 \%$ de las mujeres entrevistadas tenía más de tres hijos.

Uno de los datos más significativos que nos muestran la división del trabajo y los papeles que juegan los miembros del grupo familiar, es lo referente al trabajo doméstico y al cuidado de los niños. Al respecto, la encuesta hace evidente la frecuencia y persistencia de los papeles tradicionales de estas mujeres que la crisis hizo ingresar al mercado de trabajo. En este sentido, a pesar de su participación en la actividad económica y su contribución al ingreso familiar, siguieron siendo ellas mismas, en su gran mayoría o en su caso, sus familias, quienes se encargaban de las labores domésticas y del cuidado de los niños. Por ejemplo, $42.45 \%$ de las entrevistadas declaró que ellas mismas se las arreglaban para efectuar las labores del hogar; en $39.39 \%$, eran otros miembros de la familia quienes las efectuaban y únicamente $1.52 \%$ declaró que el marido era el encargado de estas actividades. Recordemos que las mujeres unidas constituían $62.12 \%$ de la muestra.

\section{Vendedoras ambulantes según participación doméstica}

\begin{tabular}{lc}
\hline Participación doméstica & Porcentaje \\
\hline La entrevistada & 45.45 \\
Su pareja & 1.52 \\
La familia & 39.39 \\
La sirvienta & 1.52 \\
Los hijos & 12.12 \\
\hline
\end{tabular}

Fuente: encuesta a vendedoras ambulantes del Centro Histórico de la Ciudad de México.

Con relación al cuidado de los niños, los resultados son más preocupantes puesto que $24.24 \%$ de las entrevistadas declararon que ellas mismas se ocupaban de los niños llevándolos al trabajo y $25.7 \%$ señaló que los niños permanecían solos en sus casas puesto que no tenían ni la alternativa familiar para su cuidado, ni la social (guarderías públicas); otro $25.76 \%$ refirió que sus familias las ayudaban a cuidar a los niños; destaca el hecho de que ninguna señaló que el marido se ocupara de esta actividad. 
CIUDAD, MUJER Y CONFLICTO: EL COMERCIO AMBULANTE EN EL D.F. 667

Vendedoras ambulantes según el cuidado de los niños

\begin{tabular}{lc}
\hline Cuidado de los hijos & Porcentaje \\
\hline La entrevistada & 32.00 \\
La familia & 75.76 \\
Solos & 25.76 \\
No se aplica & 24.24
\end{tabular}

Fuente: encuesta a vendedoras ambulantes del Centro Histórico de la Ciudad de México.

Quizá estos datos adquieran mayor relevancia al relacionarse con el tiempo que estas mujeres destinan a su trabajo y con la cercanía o lejanía entre éste y sus hogares. En este sentido, $74.25 \%$ de las entrevistadas destinaban entre ocho y 15 horas a su trabajo, lo cual desde cualquier perspectiva es una jornada bastante prolongada, sobre todo si se considera que $57.57 \%$ de ellas tiene su lugar de residencia en la periferia de la ciudad de México. Estamos pues, ante un tiempo dedicado a actividades vinculadas al trabajo extradoméstico sumamente prolongado, al cual habría que aumentarle las horas dedicadas al trabajo doméstico, para tener una idea de las condiciones y la calidad de vida de estas mujeres que se ocupan del comercio ambulante.

Vendedoras ambulantes por horas de trabajo extradoméstico

\begin{tabular}{cc}
\hline Horas de trabajo al día & Porcentaje \\
\hline $4-7$ & 25.76 \\
$8-11$ & 69.70 \\
$12-15$ & 4.55
\end{tabular}

Fuente: encuesta a vendedoras ambulantes del Centro Histórico de la Ciudad de México.

Vendedoras ambulantes por domicilio

\begin{tabular}{lc}
\hline Domicilio & Porcentaje \\
\hline Periferia, D.F. & 57.57 \\
Zona Centro & 42.43 \\
\hline
\end{tabular}

Fuente: encuesta a vendedoras ambulantes del Centro Histórico de la Ciudad de México.

La actividad a la que se dedican estas mujeres y las características del espacio en el que efectúan sus actividades, esto es, e] Centro Histórico de la Ciudad de México, añade una complejidad mayor a su participación económica. Esto se traduce en inseguri- 
dad laboral (con efectos en los ámbitos familiar e individual), en conflicto, en falta de alternativas, en actitudes de rechazo o de indiferencia ante los partidos políticos o el gobierno, además de los problemas presentes ya en la misma naturaleza ambulante de la actividad.

Por ejemplo, $53.03 \%$ de las vendedoras declaró que su trabajo era inseguro puesto que era una actividad laboral sujeta a problemas con los proveedores; por el carácter temporal de algunos de los productos que venden; por los conflictos con los comerciantes establecidos; por la inestabilidad de las relaciones políticas entre los distintos sujetos que están involucrados en esta actividad y las autoridades capitalinas, lo cual puede favorecer o afectar los intereses de los ambulantes; por las formas conflictivas que asume su actividad por el hecho de que depende de la relación con sus líderes y de éstos con los partidos políticos y con el gobierno; por el carácter irregular de la concesión del uso del suelo y por el acoso constante de los patrulleros que las extorsionan.

Hay que tener en cuenta que $54.55 \%$ de las vendedoras ambulantes estudiadas tenía en esta actividad su única fuente de ingresos. Para $19.7 \%$ no existía otra alternativa laboral. Es notorio que únicamente $15.15 \%$ de ellas señaló que el comercio ambulante era una actividad en la que deseaba permanecer.

Por otra parte, la mayoría de ellas indicó que formaba parte de una organización [56.06\%] y de éstas $43.94 \%$ afirmó pertenecer al PRI. De las integrantes de alguna organización, 43.94\% declaró cierta injerencia en la toma de decisiones de su grupo y se consideró de alguna manera involucrada en los aspectos relacionados con el desarrollo de su actividad. El 43.94\% sostuvo que sí contaban con el apoyo de sus representantes. En cambio, únicamente $24.24 \%$ señaló apoyar y estar de acuerdo con las políticas estatales, mientras que $60.6 \%$ manifestó desacuerdo o indiferencia ante el gobierno.

\section{Mujeres de doble jornada}

En esta categoria hemos agrupado a aquellas vendedoras ambulantes que cumplen jornadas de trabajo de entre ocho y 11 horas y además se encargan del cuidado de los niños y del trabajo doméstico en general. En este grupo quedaron incluidas 12 mujeres, esto es, $18.18 \%$ de la muestra. Sus características generales son las siguientes:

En su mayoría, estas mujeres tienen entre 20 y 39 años de edad $[91.6 \%$, lo cual indica que son relativamente jóvenes. 
Mujeres con doble jornada por grupos de edad

\begin{tabular}{cc}
\hline Edad & Porcentaje \\
\hline $20-24$ & 8.3 \\
$25-29$ & 25.0 \\
$30-34$ & 25.0 \\
$35-39$ & 33.3 \\
$60-64$ & 8.3 \\
\hline
\end{tabular}

Fuente: encuesta a vendedoras ambulantes del Centro Histórico de le Ciudad de México.

Un dato significativo para comprender las condiciones de vida en el interior del hogar y los papeles existentes entre hombre y mujer (como pareja), es el relacionado con la proporción de mujeres unidas de la muestra. En este sentido, la submuestra de mujeres con doble jornada nos indica que $83.3 \%$ de ellas estaban unidas al momento de la entrevista (casadas o en unión libre). Por lo tanto, eran mujeres que mantenían arreglos de pareja en los cuales sus maridos no se ocupaban de las labores domésticas, aun cuando ellas cumplían largas jornadas de trabajo fuera del hogar.

Mujeres con doble jornada según el estado civil

\begin{tabular}{lc}
\hline Estado civil & Porcentaje \\
\hline Unidas & 83.3 \\
Viudas & 16.7 \\
\hline
\end{tabular}

Fuente: encuesta a vendedoras ambulantes del Centro Histórico de la Ciudad de México.

Otro dato que resalta es el relativo al número de hijos. A diferencia de la muestra total, el grupo de doble jornada tiene predominantemente entre uno y dos hijos $(50.0 \%)$. La proporción de las que tenían entre tres y cuatro fue de $41.7 \%$. Respecto al nivel de educación, la mitad contaba con la primaria incompleta y la otra mitad con primaria y secundaria completas.

Mujeres con doble jornada por número de hijos

\begin{tabular}{lc}
\hline Número de hijos & Porcentaje \\
\hline $1-2$ & 50.0 \\
$3-4$ & 41.7 \\
$5-6$ & 8.3 \\
\hline
\end{tabular}

Fuente: encuesta a vendedoras ambulantes del Centro Histórico de la Ciudad de México. 


\section{Mujeres con doble jornada por nivel escolar}

\begin{tabular}{lc}
\hline Nivel escolar & Porcentaje \\
\hline Primaria incompleta & 50.0 \\
Primaria completa & 16.7 \\
Secundaria completa & 33.3 \\
\hline
\end{tabular}

Fuente: encuesta a vendedoras ambulantes del Centro Histórico de la Ciudad de México.

En torno al empleo, los datos señalan que $50 \%$ de la submuestra sólo contaba con un familiar ocupado y $41.7 \%$ con dos. Por su parte, $66.7 \%$ de estas mujeres con doble jornada tenía su domicilio.en la periferia de la ciudad de México, por lo que el acceso a su trabajo le ocupaba una gran proporción del tiempo destinado a la jornada extradoméstica. Además, a diferencia de la muestra total, estas mujeres eran en mayor medida migrantes (66.7\%) y $50.0 \%$ tenía una antigüedad en la residencia actual de hasta 10 años. El $91.7 \%$ vivía en un tipo de familia nuclear, lo cual da cuenta de la ausencia de apoyo para las labores domésticas y el cuidado de los niños fuera del propio grupo de parentesco más estrecho. Esto se manifiesta también por el número de miembros del hogar, el cual era de entre uno y dos en $96.6 \%$ de los casos de mujeres de doble jornada.

Mujeres con doble jornada por número de familiares ocupados

\begin{tabular}{cc}
\hline Miembros & Porcentaje \\
\hline Uno & 50.0 \\
Dos & 41.7 \\
Tres & 8.3 \\
\hline
\end{tabular}

Fuente: encuesta a vendedoras ambulantes del Centro Histórico de la Ciudad de México.

Mujeres con doble jornada según su domicilio

\begin{tabular}{lc}
\hline Domicilio & Porcentaje \\
\hline Periferia, D.F. & 66.7 \\
Zona Centro & 33.3 \\
\hline
\end{tabular}

Fuente: encuesta a vendedoras ambulantes del Centro Histórico de la Ciudad de México

Mujeres con doble jornada por condición migratoria

\begin{tabular}{cc}
\hline Migrante & Porcentaje \\
\hline Sí & 66.7 \\
No & 33.3 \\
\hline
\end{tabular}

Fuente: encuesta a vendedoras ambulantes del Centro Histórico de la Ciudad de México 
CIUDAD, MUJER Y CONFLJCTO: EL COMERCIO AMBULANTE EN EL D.F. 671

Mujeres con doble jornada según tipo de familia

\begin{tabular}{cc}
\hline Tipo de familia & Porcentaje \\
\hline Nuclear & 91.7 \\
Ampliada & 8.3 \\
\hline
\end{tabular}

Fuente: encuesta a vendedoras ambulantes de] Centro Histórico de la Ciudad de México.

Mujeres con doble jornada por tamaño de familia

\begin{tabular}{cc}
\hline Miembros & Porcentaje \\
\hline $1-3$ & 33.3 \\
$4-6$ & 58.3 \\
$13-15$ & 8.3 \\
\hline
\end{tabular}

Fuente: encuesła a vendedoras ambulantes del Centro Históríco de la Ciudad de México.

En lo que se refiere a los ingresos obtenidos por estas mujeres dentro de su actividad, $58.3 \%$ declaró ganar hasta 500 mil pesos al mes y $25 \%$ entre 500 mil y un millón de pesos. Este ingreso debe ser comparado con el salario mínimo vigente al momento de la encuesta, que en ese periodo fluctuaba alrededor de los $300 \mathrm{mil} \mathrm{pe}-$ sos mensuales en la ciudad de México.

Mujeres con doble jornada por ingresos familiares

\begin{tabular}{cc}
\hline $\begin{array}{c}\text { Ingresos familiares/ } \\
\text { diarios y en pesos }\end{array}$ & Porcentaje \\
\hline $1-1000$ & 83.3 \\
$2001-3000$ & 8.3 \\
$4001-5000$ & 8.3 \\
\hline
\end{tabular}

Fuente: encuesta a vendedoras ambulantes del Centro Histórico de la Ciudad de México.

La mayor parte de estas mujeres señalaron que ellas son las propietarias de sus puestos, esto es, $83.3 \%$. Sólo una de ellas declaró tener seguridad en su trabajo; en cambio $91.7 \%$ indicó que tiene poca o ninguna seguridad laboral. El $66.6 \%$ de las mujeres entrevistadas señalaron que ingresaron a esta actividad por carecer de alternativas económicas. Un $33.3 \%$ afirmaron que continúan en esta actividad por motivos de comodidad o facilidad y otro $33.35 \%$ indicaron que lo ejercían porque no tenían otra posibilidad económica. De estas mujeres, $33.3 \%$ no ve ninguna pers- 
pectiva a futuro en su trabajo, en tanto que $25 \%$ plantea mantenerse en el comercio ambulante.

De las mujeres con doble jornada entrevistadas, $58.3 \%$ señalaron que estaban organizadas y $41.7 \%$ expresaron que pertenecían al PRI; $41.7 \%$ tenía una participación activa en su organización. Destaca el hecho de que $58.3 \%$ de las mujeres con doble jornada hayan señalado que no tienen impedimentos para efectuar su tra-: bajo y que únicamente dos de ellas (16.7\%) aludieron a problemas con el cobro dé las cuotas por el uso del suelo. El 50\% de estas mujeres declararon que contaban con el apoyo de sus representantes para la gestión de los diversos aspectos de su actividad. En cambio, $75 \%$ de ellas expresaron su desacuerdo con el gobierno y $58.4 \%$ señalaron que o no apoyaban o les resultaba indiferente la labor de los partidos políticos.

\section{Conclusiones}

Los datos que hemos presentado en este trabajo, provenientes de la encuesta aplicada a un grupo de vendedoras ambulantes de la ciudad de México, nos permiten apuntar hacia una caracterización general, que aun cuando proveniente de un grupo especffico de mujeres, podrian explicar en alguna medida las condiciones de vida de otros sectores de la población femenina de la ciudad o del país en su conjunto.

Por una parte, destacan las pesadas jornadas laborales a las que se someten estas mujeres, así como las actividades familiares en las que participan y que refuerzan la carga de trabajo, al añadir al trabajo extradoméstico, el propio del hogar, en lo referente a la elaboración de los medios de subsistencia en general y al cuidado de los niños en particular. La incorporación de la mujer a la actividad económica no implica la supresión del trabajo doméstico, sino que se le suma.

Por otra parte, la actividad ambulante significa un trabajo que además de la inestabilidad territorial del espacio físico en el que se lleva a cabo, implica una inseguridad de carácter económico por las fluctuaciones inherentes a los periodos de oferta y demanda de los productos que comercializan. A lo anterior, se debe sumar la inestabilidad que deriva del carácter político de la gestión del espacio ocupado; espacio que depende de las correlaciones de fuerza y del momento político en los que participan los distintos actores involucrados, ya sean éstos los comerciantes organizados, el gobierno capitalino, los partidos políticos, las organizaciones de ambulantes, etc. Todos estos elementos se traducen en condicio- 
nes desfavorables para el desempeño del trabajo de estas mujeres.

Habría que ver también algunas consecuencias en la organización familiar y en los procesos de socialización de los hijos, los cuales o permanecen solos en sus hogares o son llevados con sus madres a los ámbitos laborales cuando no cuentan con apoyo familiar para ser atendidos.

Algunas de las consecuencias observadas en estas mujeres son: la falta de perspectivas, la incertidumbre ante el futuro, el rechazo a las organizaciones partidistas y al gobierno, así como la permanencia en una actividad que muchas veces deploran, pero en la que tienen que permanecer por falta de alternativas.

La crisis y las modificaciones en los procesos capitalistas no inventaron el comercio ambulante, pero sí incrementaron su práctica y, en muchas de sus variantes, lo convirtieron en un canal de distribución de las mercancías a bajo costo; por lo tanto, en estrategia de reproducción del capital. Pero lo que efectivamente no nace con estos procesos, son las condiciones de vida y las relaciones de subordinación y de extorsión del trabajo femenino que derivan de la participación en papeles provenientes de una desigual división del trabajo en el ámbito familiar. El trabajo femenino ya ha sido conceptualizado por diversos autores bajo sus formas de valor de uso o de valor de cambio, directa o indirectamente vinculado con la creación de mercancías, y por lo tanto, con la explotación; pero al ser pensado como actividad natural, como inherente a una condición femenina, y como trabajo que no se expresa transparentemente en un producto completamente perceptible, aparece como "no trabajo"; por ello se dice que la mujer no trabaja, que sólo se ocupa del hogar. La crisis, al empujar a muchas mujeres al trabajo extradoméstico, no ha hecho sino exponer en toda su dimensión la naturaleza desigual de las relaciones en el interior de las familias, en las cuales anidan las fuentes del conflicto, sea que éste se exprese en su forma manifiesta o abierta, o sea que se viva únicamente como estado de impotencia o violencia contenida.

Por último, es importante señalar que falta mucho por hacer en el campo de los estudios urbanos concretos; en esta ocasión sólo se ha mostrado un aspecto, de manera preliminar, referente a la problemática urbana en el que se contempla la complejidad que asumen los problemas sociales, cuando además de su componente territorial se le añade su contenido de género. Es necesario efectuar investigaciones particulares en las cuales, además de rescatarse las condiciones socioeconómicas en las que se efectúa el trabajo femenino, se analice el protagonismo real de la mujer en los distintos ámbitos de la vida social, ya se trate de la familia, lo económico, lo político o lo cultural. En cada uno de estos espacios 
la mujer añade una especificidad a los procesos y esto es lo que debe ser rescatado cuando se realizan estudios bajo tal perspectiva.

En tanto a la formulación de políticas referentes al comercio ambulante que beneficie a la mujer, el problema es sumamente complejo. Por una parte, el comercio ambulante tiende a ubicarse siguiendo la lógica del mercado. El Centro Histórico es un gran ámbito de concentración demográfica y también de densificación de la actividad comercial. Además del tránsito de consumidores de las mercancías que venden los ambulantes, también existe allí un gran número de bodegas y comerciantes mayoristas que los proveen de sus productos.

Es prácticamente imposible desaparecer al ambulantaje, porque esto significaria no sólo hacer desaparecer la crisis, sino también los mecanismos actuales de comercialización de muchas empresas capitalistas que hallan en las actividades ambulantes un importante mecanismo de disminución de costos; por lo tanto, lo que debe plantearse más bien es una adecuada reglamentación que defina las normas con las que se practicará esta actividad y que establezca condiciones de trabajo más humanas para quienes la efectúan, trátese de hombres o de mujeres. En el caso del Centro Histórico, aparte de su contenido simbólico y de sus usos en la industria turística, para las mujeres que allí laboran en el ambulantaje, es sobre todo un espacio de reproducción económica. Por ello, las propuestas de políticas para reubicar a los ambulantes o la construcción de mercados para que efectúen allí sus actividades, están condenadas al fracaso. Los ambulantes se instalan en donde están quienes demandan sus productos, ésta es la lógica principal de su ubicación territorial.

\section{Bibliografía}

Alonso, Jorge [1984], "Notas acerca de la situación de los pobladores depauperados y su relación con el movimiento urbano popular", en Nueva Antropología, vol. '̌, núm. 24, México, pp. 35-50.

Benholdt-Thomsen, Verónica (1981), "Marginalidad en América Latina: critica a la teoría", en Revista Mexicana de Sociología, vol. 43, núms. 3-4: 131-153.

Borja. Jordi (1975). Movimientos sociales urbanos, Buenos Aires, SIAP.

Castells. Manuel (1985). La ciudad y las masas, México. Alianza Editorial.

Cisneros, Armando (1985). Políticas urbanas y mercado inmobiliario en el Centro Histórico. México. INAlt.

Encuesta a Vendedoras Ambulantes del Centro Histórico de la Ciudad de México.

García. Brigida y Orlandina de Oliveira [1989). "El nuevo perfi] del traba- 
jo femenino: 1976-1987", México, IV Reunión Nacional de Investigación Demográfica.

y Humberto Muñoz (1979), "Migración, familia y fuerza de trabajo en la Ciudad de México", en Cuadernos de CES, núm. 26, México, El Colegio de México.

(1983), Familia y mercado de trabajo; un estudio de dos ciudades brasileñas, México, El Colegio de México.

Hansen, Roger (1983), La política del desarrollo mexicano, México, Siglo XXI Editores.

Hewitt de Alcántara, Cynthia (1977), "Ensayo sobre la satisfacción de necesidades básicas del pueblo mexicano entre 1940 y 1970", en Cuadernos de CES, núm. 21, México, El Colegio de México.

Margulis, Mario (s/f), "Reproducción de la unidad doméstica, fuerza de trabajo y relaciones de producción".

Meillasoux (1983), Mujeres, graneros y capital, México, Siglo XXI Editores.

Moctezuma, Pedro (1984), "El movimiento urbano popular mexicano", en Nueva Antropología, vol. vi, núm. 24, México, pp. 61-87.

Montaño, Jorge (1976), Los pobres de la ciudad en los asentamientos espontáneos, México, Siglo XXI Editores.

Navarro, Bernardo (1986), Crisis y movimiento urbano popular en el Valle de México, México, Ediciones de la Casa Chata.

Ortega, Ernesto (1989), "Las organizaciones vecinales y las políticas habjtacionales después de los sismos", tesis de maestría, El Colegio de México.

Perló, Manuel y Martha Schteingart (1984), "Movimientos sociales urbanos en México", en Revista Mexicana de Sociología, vol. 46, núm. 4, pp. 105-125.

Schteingart, Martha y José Luis Lezama [1986), "El impacto social del sismo en la Ciudad de México", en Estudios Latinoamericanos, vol. 1, pp. 29-37.

Touraine, Alain (1987), El regreso del actor, Buenos Aires, Eudeba.

Unikel, Luis, Crescencio Ruiz Chiapetto y Gustavo Garza (1976), El desarrollo urbano de México, México, E] Colegio de México. 